\title{
Luteolin inhibits respiratory syncytial virus replication by regulating the MiR-155/SOCS1/ STAT1 signaling pathway
}

\author{
Saisai Wang ${ }^{1}$, Yiting Ling ${ }^{1}$, Yuanyuan Yao ${ }^{1}$, Gang Zheng ${ }^{2}$ and Wenbin Chen ${ }^{1 *}$ (D)
}

\begin{abstract}
Background: Respiratory syncytial virus (RSV) is a major cause of acute lower respiratory tract infection in infants, children, immunocompromised adults, and elderly individuals. Currently, there are few therapeutic options available to prevent RSV infection. The present study aimed to investigate the effects of luteolin on RSV replication and the related mechanisms.
\end{abstract}

Material and methods: We pretreated cells and mice with luteolin before infection with RSV, the virus titer, expressions of RSV-F, interferon (IFN)-stimulated genes (ISGs), and production of IFN- $\alpha$ and IFN- $\beta$ were determined by plaque assay, RT-qPCR, and ELISA, respectively. The activation of Janus kinase (JAK)-signal transducer and activator of transcription 1 (STAT1) signaling pathway was detected by Western blotting and luciferase assay. Proteins which negatively regulate STAT1 were determined by Western blotting. Then cells were transfected with suppressor of cytokine signaling 1 (SOCS1) plasmid and virus replication and ISGs expression were determined. Luciferase reporter assay and Western blotting were performed to detect the relationship between SOCS1 and miR-155.

Results: Luteolin inhibited RSV replication, as shown by the decreased viral titer and RSV-F mRNA expression both in vitro and in vivo. The antiviral activity of luteolin was attributed to the enhanced phosphorylation of STAT1, resulting in the increased production of ISGs. Further study showed that SOCS1 was downregulated by luteolin and SOCS1 is a direct target of microRNA-155 (miR-155). Inhibition of miR-155 rescued luteolin-mediated SOCS1 downregulation, whereas upregulation of miR-155 enhanced the inhibitory effect of luteolin.

Conclusion: Luteolin inhibits RSV replication by regulating the miR-155/SOCS1/STAT1 signaling pathway.

Keywords: Respiratory syncytial virus (RSV), Luteolin, Suppressor of cytokine signaling 1 (SOCS1), microRNA-155 (miR-155), Signal transducer and activator of transcription 1 (STAT1)

\section{Background}

Human respiratory syncytial virus (RSV) is an enveloped, negative-sense, single-strand RNA (ssRNA) virus of the Pneumoviridae family [1]. RSV is the primary cause of respiratory infection in infants and children, resulting

\footnotetext{
*Correspondence: wenbinchen@zju.edu.cn

${ }^{1}$ Department of Colorectal Surgery, The First Affiliated Hospital, Zhejiang University School of Medicine, 79 Qingchun Road, Hangzhou 310003, Zhejiang, People's Republic of China

Full list of author information is available at the end of the article
}

in pneumonia and bronchiolitis. Moreover, severe RSV infection is related to the development of recurrent wheezing or asthma [2]. In elderly individuals (65 years of age or older), RSV is also an important cause of respiratory infection [3]. Although continuous progress has been made in the development of an RSV vaccine [4], effective treatment against RSV is still urgently needed.

In natural infections, RSV replicates primarily in the airway epithelium. RSV infection or uptake by airway epithelial cells induces a direct antiviral response through the production of cytokines and chemokines. A549 cells original author(s) and the source, provide a link to the Creative Commons licence, and indicate if changes were made. The images or other third party material in this article are included in the article's Creative Commons licence, unless indicated otherwise in a credit line to the material. If material is not included in the article's Creative Commons licence and your intended use is not permitted by statutory regulation or exceeds the permitted use, you will need to obtain permission directly from the copyright holder. To view a copy of this licence, visit http://creativecommons.org/licenses/by/4.0/. The Creative Commons Public Domain Dedication waiver (http://creativeco mmons.org/publicdomain/zero/1.0/) applies to the data made available in this article, unless otherwise stated in a credit line to the data. 
(a human pulmonary alveolar cell carcinoma cell line with epithelial type II cell properties) are often used in RSV research. Type I interferons (IFNs), including IFN- $\alpha$ and IFN- $\beta$, are rapidly induced during viral infection and play a central role in restricting viral replication through the induction of a variety of antiviral effectors [5].

Luteolin (Fig. 1a) is a common bioflavonoid found in a variety of fruits and vegetables. Luteolin has been reported to possess numerous beneficial medicinal properties, such as its anti-tumor, anti-inflammatory, cardioprotective, and neuroprotective effects [6-9]. Luteolin has been reported to exert inhibitory effects on dengue virus, Epstein-Barr virus (EBV), Japanese encephalitis virus, hepatitis $B$ virus, and hepatitis $C$ virus [10-14]. The mechanisms of these inhibitory effects include activation of extracellular signal-regulated kinase, downregulation of hepatocyte nuclear factor 4 , inhibition of the host proprotein convertase furin, and repression of the EBVinduced promotion of immediate-early genes. Liu et al. reported that luteolin does not affect the replication of pseudorabies virus (PRV) in RAW264.7 cells but inhibits the expression of JAK, signal transducer and activator of transcription 1 (STAT1), STAT3, pSTAT1 and pSTAT3 [15]. Due to these properties, interest in the role of luteolin in RSV infection has increased.

MicroRNAs (miRNAs) are a class of small noncoding RNAs of $\sim 22 \mathrm{nt}$ in length that usually exert their effects through directly binding to the $3^{\prime}$-untranslated regions (UTRs) of their target mRNAs [16], resulting in the degradation of these mRNAs or their translational inhibition [17, 18]. MicroRNA-155 (miRNA-155), a tumor-promoting miRNA, is processed from the $B$ cell integration cluster. Studies have reported that miR-155 directly targets SHIP1, WEE1, VHL, TP53INP1, PU.1, BCL2, BCL6, SOCS1, and SOX family genes [19-21].

In this study, we demonstrated that luteolin has novel antiviral effect on RSV replication by inducing the expression of miR-155, which directly targets SOCS1, a negative regulator of STAT1 [22], leading to the upregulation of STAT1 phosphorylation and IFN-stimulated genes (ISGs) expression.

\section{Materials and methods Reagents}

Luteolin ( $\geq 98 \%$, HPLC) was purchased from SigmaAldrich (Shanghai, China) and dissolved in DMSO as a stock solution. Enzyme-linked immunosorbent assay (ELISA) kits for human and mouse IFN- $\alpha$ and IFN- $\beta$ were purchased from R\&D Systems (Minneapolis, MN). Anti-

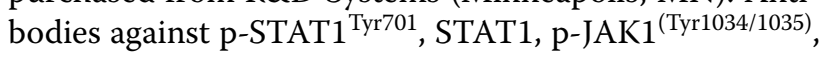
JAK1, SOCS1, SOCS2, SOCS3, SOCS6, SHP-1, SHP-2 were purchased from Cell Signaling Technology (Danvers, MA, USA). Antibodies against CIS and GAPDH were purchased from Santa Cruz Biotechnology (Santa Cruz, CA). A Cell Counting Kit-8 (CCK-8) and horseradish peroxidase-conjugated goat anti-rabbit antibody were purchased from Beyotime Institute of Biotechnology (Haimen, China).

\section{Cell culture and treatment}

HEp-2 and A549 cells were obtained from American Type Culture Collection (ATCC) and cultured in DMEM supplemented with $10 \%$ fetal bovine serum (FBS), 100 $\mathrm{U} / \mathrm{mL}$ penicillin, and $100 \mu \mathrm{g} / \mathrm{mL}$ streptomycin at $37^{\circ} \mathrm{C}$ in a humidified atmosphere of $5 \% \mathrm{CO}_{2}$. Human pulmonary alveolar epithelial cells (HPAEpiC) were purchased from SciencCell (Shanghai, China) and cultured in complete alveolar epithelial cell medium (AEpiCM). Murine embryonic fibroblasts (MEFs) were obtained from C57BL/6 mouse embryos (14 days) and cultured in complete DMEM. AEpiCM was purchased from ScienCell and all the other culture reagents were purchased from Gibco (Shanghai, China). Cells were pretreated with vehicle or luteolin at the indicated concentrations for $24 \mathrm{~h}$ before infected with RSV at a multiplicity of infection (MOI) of 0.05. At different hours post infection (hpi), the whole cell culture was collected for plaque assay, supernatants were collected for ELISAs, or the cells were collected for RNA or protein extraction.

\section{Virus}

The long strain of RSV was obtained from ATCC and propagated in HEp- 2 cells. Briefly, the virus was added to

\footnotetext{
(See figure on next page.)

Fig. 1 Luteolin inhibits RSV replication in A549 cells and MEFs. a Chemical structure of luteolin. b A549 cells were treated with the indicated concentrations of luteolin for 24, 48, 72, 96 and $120 \mathrm{~h}$. Cell proliferation was measured by CCK-8 assay. c A549 cells were pre-treated with the indicated concentrations of luteolin for $24 \mathrm{~h}$ before infected with RSV at MOI $=0.05$. After infection for 12, 24, 48, 72 and $96 \mathrm{~h}$, cell culture medium was collected for plaque assay to determine the virus titer. A549 cells, MEFs and HPAEpiC cells were pre-treated with the indicated concentrations of luteolin for $24 \mathrm{~h}$ before infected with RSV at $\mathrm{MOI}=0.05$. At the indicated hours post infection, $\mathbf{d}$ virus titer was determined by plaque assay and e RSV-F mRNA expression was determined by RT-qPCR. f A549 cells were pre-treated or treated simultaneously with RSV infection or treated after RSV infection at $\mathrm{MOI}=0.05 .48 \mathrm{~h}$ post infection, cell culture medium was collected for plaque assay to determine the virus titer. Data shown are means \pm SEM. Statistical significance was examined by Students' $t$-test. $P<0.05$ was considered statistically significant. ${ }^{*} P<0.05,{ }^{* *} P<0.01,{ }^{* * * *} P<0.001$. RSV respiratory syncytial virus, CCK-8 Cell Counting Kit-8, $\mathrm{MO}$ I multiplicity of infection
} 


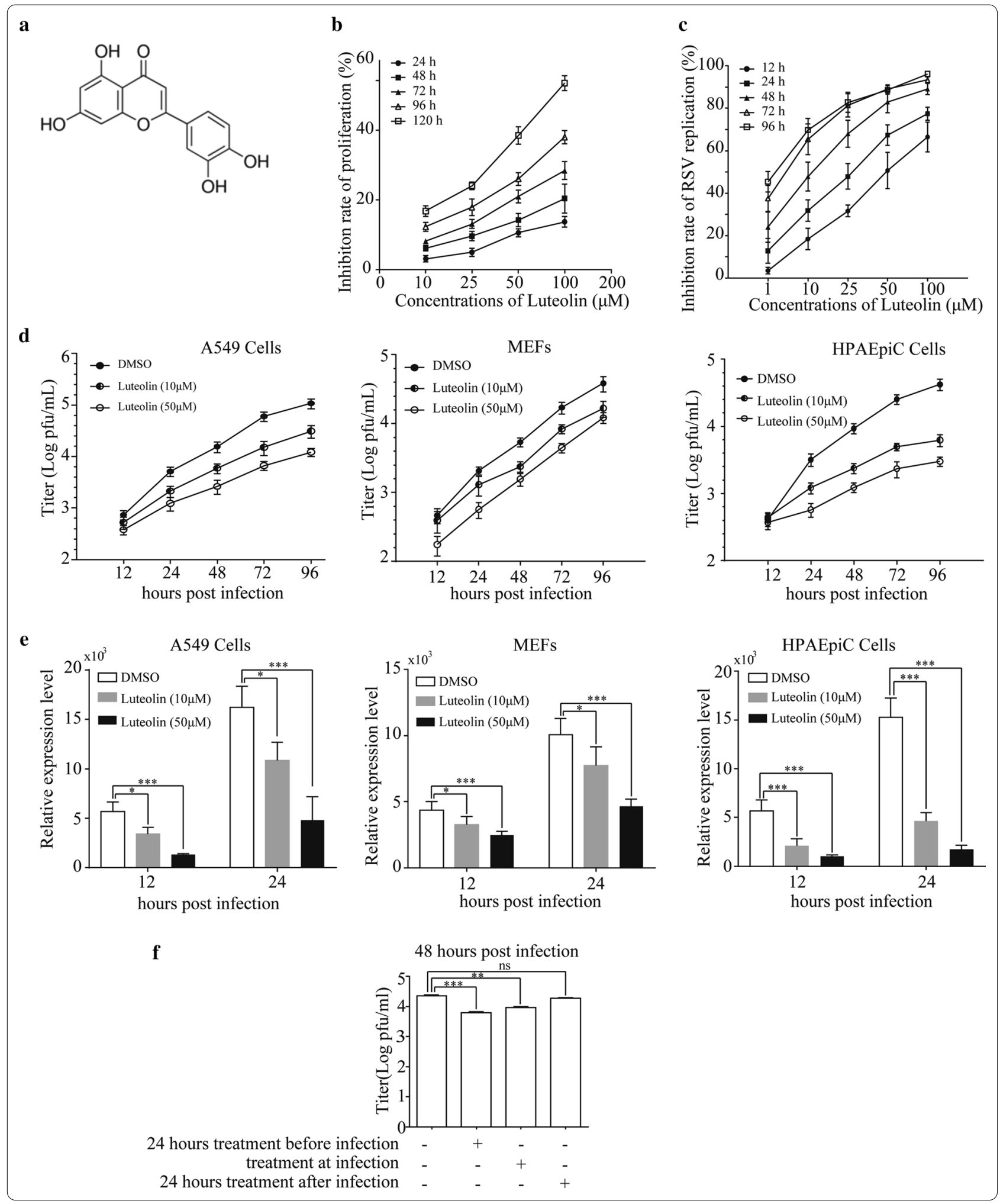


a monolayer of HEp-2 cells and allowed to absorb for $2 \mathrm{~h}$ with rocking every $15 \mathrm{~min}$. After $2 \mathrm{~h}$ of absorption, the medium was replaced with DMEM containing $2 \%$ FBS. Cells were left to grow for another 4-5 days until $80-90 \%$ cytopathic effects (CPE) were observed, and then the entire cell culture was collected. After three freeze-thaw cycles, the viruses were collected by centrifugation at $50,000 \mathrm{~g}$ for $1.5 \mathrm{~h}$ at $4{ }^{\circ} \mathrm{C}$, and the remaining pellet was resuspended, aliquoted and stored at $-80{ }^{\circ} \mathrm{C}$ before use. Plaque forming units (PFU) were determined by plaque assays with HEp- 2 cells.

To determine the $\mathrm{EC}_{50}$ (concentration for $50 \%$ of maximal effect) value of luteolin against RSV infection, A549 cells were pretreated with various concentrations of luteolin before infected with RSV. After infection for 12, $24,48,72$ and $96 \mathrm{~h}$, the culture medium was collected for plaque assays to determine the viral titer. The viral replication inhibition rate was expressed as the percentage of viral replication compared to that in the DMSO-treated cells, and the $\mathrm{EC}_{50}$ was calculated. The selectivity indexes (SIs) for the various time points were calculated with the following equation: $\mathrm{SI}=\mathrm{CC}_{50} / \mathrm{EC}_{50}$. The $\mathrm{CC}_{50}$ value (concentration of drug required to reduce cell viability by $50 \%$ of luteolin in A549 cells was determined by CCK- 8 assay.

\section{Plaque assay}

Viral titer was determined by the plaque assay. HEp-2 cells were plated into 12-well plates and allowed to grow into a monolayer. Virus stocks, cell-free medium or lung homogenates from the mice were serially diluted tenfold at a volume of $200 \mu \mathrm{L}$ and then incubated with HEp-2 cells. After 1-h incubation, the supernatants were removed, and the cells were overlaid with $1 \mathrm{~mL}$ of $1 \%$ (wt/vol) methylcellulose containing 50\% (vol/vol) DMEM and 2\% (vol/vol) FBS and cultured for another 5 days before the overlay medium was removed. Cells were fixed and stained with $2 \%$ (wt/vol) crystal violet in $20 \%$ (vol/ vol) ethanol. The plaques were observed, and plaques in wells containing 30-100 plaques were counted. Viral titers were calculated using the following formula: viral titer $(\mathrm{PFU} / \mathrm{mL})=$ plaques $\times$ dilution $\times 5$.

\section{CCK-8 assay}

The $\mathrm{CC}_{50}$ value of luteolin in A549 cells was determined by the CCK- 8 assay. A549 cells were plated into 96-well plates at a density of $1 \times 10^{3} /$ well. Twenty-four hours later, the culture media were replaced with media containing various concentrations of luteolin. After culturing for 24, 48, 72, 96 and $120 \mathrm{~h}, 10 \mu \mathrm{L}$ of CCK-8 solution (Beyotime Institute of Biotechnology, Haimen, China) was added, and the cells were cultured for another hour before absorbance (Ab.) at $490 \mathrm{~nm}$ was measured using an ELISA microplate reader (EL800, BioTek Instruments, Winooski, VT, USA). The cell inhibition rate (I\%) was calculated using the following equation: $\mathrm{I} \%=(\mathrm{Ab}$. control $-\mathrm{Ab}$. treated)/Ab. control $\times 100 \%$. The $\mathrm{CC}_{50}$ value was determined.

\section{mRNA and miRNA quantification by reverse transcription-quantitative polymerase chain reaction (RT-qPCR) analysis}

Total cellular RNA was extracted from cultured cells or lung homogenates with TRIzol reagent (Invitrogen). To analyze mRNA expression, $1 \mu \mathrm{g}$ of RNA was reverse transcribed to cDNA with a PrimeScript RT Reagent Kit (TaKaRa, Beijing, China), and quantitative real-time PCR was then performed with SYBR Green qPCR Master Mix (TaKaRa). Sequences of the primers used for RT-qPCR are listed in Table 1 . The calculated threshold cycle was

Table 1 Primer sequences used in the experiment

\begin{tabular}{|c|c|c|}
\hline Gene & Forward & Reverse \\
\hline RSV-F & TTGGATCTGCAATCGCCA & CTTTTGATCTTGTTCACTTCTCCTTCT \\
\hline $\mathrm{hMX} 1$ & GTTTCCGAAGTGGACATCGCA & CTGCACAGGTTGTTCTCAGC \\
\hline hOAS1 & TGTCCAAGGTGGTAAAGGGTG & CCGGCGATTTAACTGATCCTG \\
\hline hISG15 & CGCAGATCACCCAGAAGATCG & TTCGTCGCATTTGTCCACCA \\
\hline hIFN-a & GCCTCGCCCTTTGCTTTACT & CTGTGGGTCTCAGGGAGATCA \\
\hline hIFN- $\beta$ & CATTACCTGAAGGCCAAGGA & CAATTGTCCAGTCCCAGAGG \\
\hline h $\beta$-actin & CATGTACGTTGCTATCCAGGC & СTCCTTAATGTCACGCACGAT \\
\hline $\mathrm{mMX} 1$ & GACCATAGGGGTCTTGACCAA & AGACTTGTCTTTCTGAAAAGCC \\
\hline mOAS1b & GAGGTCCACAGTTTAAGGAGTCC & GGTACGCCCACTGATGAGATT \\
\hline mISG15 & GGTGTCCGTGACTAACTCCAT & CTGTACCACTAGCATCACTGTG \\
\hline $\mathrm{mIFN}-\mathrm{a} 4$ & TACTCAGCAGACCTTGAACCT & CAGTCTTGGCAGCAAGTTGAC \\
\hline $\mathrm{mIFN}-\beta$ & ATGAGTGGTGGTTGCAGGC & TGACCTTTCAAATGCAGTAGATTCA \\
\hline$m \beta$-actin & GTATCCTGACCCTGAAGTACC & TGAAGGTCTCAAACATGATCT \\
\hline
\end{tabular}


normalized based on the value of $\beta$-actin amplified from the same cDNA, and the fold-change in expression was calculated as referenced to expression of the control.

To analyze miRNA levels, total RNA was reverse transcribed into cDNA with the miRcute miRNA First-Stand cDNA Synthesis Kit (Tiangen Biotech Co., Ltd., Beijing, China). The miRcute miRNA qPCR Detection Kit (SYBR Green; Tiangen Biotech Co., Ltd.) was used for qPCR. U6 was served as the housekeeping gene. The specific primers for miR-155 and U6 were synthesized by GenePharma (Shanghai, China). The primer sequences were as follows: miR-155, forward 5'-CTCAACTGG TGTCGTGGAGTCGGCAATTCAGTTGAGACCCCT AT- $3^{\prime}$, reverse $5^{\prime}$-ACACTCCAGCTGGGTTAATGCTAA TCGTGAT-3'; and U6, forward 5'-CTCGCTTCGGCA GCACA-3', reverse, 5'-AACGCTTCACGAATTTGCG $\mathrm{T}-3^{\prime}$. All reactions were performed in triplicate, and the data were analyzed with the delta delta cycle threshold (CT) method of relative quantification.

\section{ELISA}

To assess the production of cytokines, cell supernatants and bronchial alveolar lavage fluid (BALF) were collected. IFN- $\alpha$ and IFN- $\beta$ levels were determined with commercial ELISA kits according to the manufacturer's instructions. The absorbance at $490 \mathrm{~nm}$ was read on an ELISA plate reader.

\section{Mouse infection}

Female BALB/c mice (5-6 weeks old) were obtained from the Shanghai Laboratory Animal Company (SLAC; Shanghai, China). Current study received ethical approval from the Animal Care and Use Committee of Zhejiang University, and experiments and animal care were performed according to the approved protocols. Mice were randomly divided into three groups as follows: (i) mockinfected: mice were mock infected (DMEM only); (ii) RSV+PBS: mice were intraperitoneally injected with PBS 24 h before RSV infection; and (iii) RSV + luteolin: mice were intraperitoneally injected with $50 \mathrm{mg} / \mathrm{kg}$ luteolin $24 \mathrm{~h}$ before RSV infection. For RSV infection, mice were anesthetized and then intranasally inoculated with $5 \times 10^{5}$ or $1 \times 10^{7}$ PFU RSV in a total volume of $20 \mu \mathrm{L}$. At 1 or 3 days postinfection (dpi), the mice were euthanized. BALFs were harvested, and the lungs were collected for RNA extraction or fixed for hematoxylin and eosin (H\&E) staining.

\section{Western blotting}

Western blotting was performed using the standard SDS-PAGE separation technique. The harvested cells were washed with ice-cold PBS twice and lysed in $1 \times$ RIPA buffer (Cell Signaling Technology, Danvers,
MA) supplemented with $1 \mathrm{mM}$ phenyl methyl sulfonyl fluoride (Solarbio, Beijing, China) and protease inhibitor cocktail. Protein concentrations were determined, and equal amounts of protein from each sample were separated by $10 \%$ SDS-PAGE and blotted onto PVDF membranes (Millipore, Billerica, MA, USA). The membranes were incubated overnight at $4{ }^{\circ} \mathrm{C}$ with antibodies against p-STAT1, total STAT1, p-JAK1, total JAK1, SOCS1, SOCS2, SOCS3, SOCS6, CIS, SHP-1, SHP-2 and GAPDH. Subsequently, the membranes were incubated with a horseradish peroxidase-conjugated goat anti-rabbit antibody for $1.5 \mathrm{~h}$ at room temperature. Immunoreactive protein bands were detected using an Odyssey scanning system (LI-COR, USA), quantified by ImageJ and normalized to the corresponding amount of total protein.

\section{Luciferase reporter assay}

For the IFN-stimulated response element (ISRE) luciferase assay, A549 cells in 96-well plates were transfected with plasmid (pISRE-TA-luc, Beyotime) harboring the firefly luciferase gene under control of the ISRE promoter (ISRE-luc) with or without cotransfection with SOCS1 expression plasmid (Ruijie, Shanghai, China) or a control plasmid (empty pcDNA3.1 vector) with Lipofectamine 2000 (Invitrogen, Carlsbad, CA). Twenty-four hours after transfection, cells were treated with luteolin or vehicle for $24 \mathrm{~h}$ before infection with RSV at MOI of 0.05 . At the indicated hpi, cells were collected, and luciferase activities were determined with the Bright-Glo luciferase assay system (Promega Corp., Madison, WI).

The reporter constructs pcDNA-Luc Wt SOCS1 (containing the $3^{\prime}$-UTR of SOCS1 downstream of the luciferase gene), pcDNA-Luc Mut SOCS1 (containing a mutated target seed sequence) and Renilla vector (reference) were synthesized by GenePharma (Shanghai, China). Cells were plated in 24-well plates and then cotransfected with pcDNA-Luc Wt SOCS1 or pcDNALuc Mut SOCS1 and miR-155 mimic or miR-155 negative control and Renilla vector using Lipofectamine 2000. Luciferase activities were analyzed using the DualLuciferase ${ }^{\circledR}$ Assay system (Promega Corp., Madison, WI, USA). Relative luciferase activity was obtained by normalizing the Renilla luciferase activity to the firefly luciferase activity.

\section{Cell transfection}

A549 cells were transfected with a SOCS1 expression plasmid or a control plasmid (empty pcDNA3.1 vector) (Ruisai Technology, Shanghai, China) with or without $50 \mathrm{nM}$ hsa-miR-155 mimic or $100 \mathrm{nM}$ hsa-miR-155 inhibitor (GenePharma, Shanghai, China) using Lipofectamine 2000 (Invitrogen, Shanghai, China) according 
Table $2 \mathrm{CC}_{50}$ values of luteolin in A549 cells

\begin{tabular}{llllll}
\hline & $\mathbf{2 4} \mathbf{h}$ & $\mathbf{4 8} \mathbf{h}$ & $\mathbf{7 2} \mathbf{h}$ & $\mathbf{9 6} \mathbf{h}$ & $\mathbf{1 2 0} \mathbf{h}$ \\
\hline $\mathrm{CC}_{50}(\mu \mathrm{M})$ & 549.4 & 339.4 & 214.9 & 143 & 79.45 \\
\hline
\end{tabular}

Table $3 \mathrm{EC}_{50}$ values and selectivity index (SI) of luteolin against RSV infection in A549 cells

\begin{tabular}{llllcc}
\hline & $\mathbf{1 2} \mathbf{h}$ & $\mathbf{2 4} \mathbf{h}$ & $\mathbf{4 8} \mathbf{h}$ & $\mathbf{7 2} \mathbf{h}$ & $\mathbf{9 6} \mathbf{h}$ \\
\hline $\mathrm{EC}_{50}(\mu \mathrm{M})$ & 49.94 & 24.71 & 10.16 & 3.552 & 2.075 \\
$\mathrm{SI}$ & & 22.23391 & 33.40551 & 60.50113 & 68.91566 \\
\hline
\end{tabular}

to the manufacturer's instructions. Control samples were transfected with a miRNA mimic negative control (miR$155 \mathrm{NC}$ ). After transfection for $6 \mathrm{~h}$, cells were washed with ice-cold PBS twice and then cultured for an additional $24 \mathrm{~h}$. The transfection efficiency was assessed by RT-qPCR or Western blotting.

\section{Statistical analysis}

All data were analyzed using SPSS 17.0 software (SPSS Inc., Chicago, IL, USA). Data are presented as the means \pm SEM. Comparisons between two groups were performed using the Student's $t$-test. $P<0.05$ indicated significance.

\section{Results}

\section{Luteolin inhibits RSV replication in A549, MEFs} and HPAEpiC cells

To elucidate the effects of luteolin on RSV replication, we first detected the $\mathrm{CC}_{50}$ values of luteolin in $\mathrm{A} 549$ cells by CCK- 8 assay. As shown in Fig. $1 \mathrm{~b}$ and Table 2, the $\mathrm{CC}_{50}$ values of luteolin in A549 cells at 24, 48, 72, 96 and $120 \mathrm{~h}$ were 549.4, 339.4, 214.9, 143 and $79.45 \mu \mathrm{M}$, respectively. We also determined the $\mathrm{EC}_{50}$ value of luteolin against RSV in A549 cells. As shown in Fig. 1c and Table 3, the $\mathrm{EC}_{50}$ values of luteolin against RSV at $12,24,48,72$ and $96 \mathrm{~h}$ were 49.94, 24.71, 10.16, 3.552 and $2.075 \mu \mathrm{M}$, respectively. Since most of the studies have focused on the early innate immune response elicited in the RSVinfected cells, we then chose concentrations of 10 and $50 \mu \mathrm{M}$ for the next experiments at which will inhibit $50 \%$ of RSV replication at 12 and $48 \mathrm{~h}$. Cells viability at 24, 48, 72 and $96 \mathrm{~h}$ after $10 \mu \mathrm{M}$ luteolin treatment were $96.9 \%$, $93.9 \%, 91.9 \%$ and $87.7 \%$, respectively. Cells viability at 24, 48, 72 and $96 \mathrm{~h}$ after $50 \mu \mathrm{M}$ luteolin treatment were $89.4 \%, 85.8 \%, 79.0 \%$ and $74.0 \%$, respectively. A549 cells, MEFs and HPAEpiC cells were pretreated with luteolin for $24 \mathrm{~h}$ before infection with RSV at MOI of 0.05. At the indicated hpi, viral titer or RSV-F mRNA expression was determined by plaque assay (Fig. 1d) or RT-qPCR (Fig. 1e), respectively. As presented, luteolin significantly inhibited RSV replication in a dose-dependent manner. We also checked the RSV replication with luteolin treatment at different times and results showed that luteolin pre-treatment or treatment simultaneously with the virus infection could inhibit the RSV replication $(P<0.05)$ (Fig. 1f). However, luteolin addition $24 \mathrm{~h}$ after RSV infection had no effects on virus replication since the difference was not significant, indicating that the preventive effect of luteolin was more obvious than therapeutic effect.

\section{Luteolin upregulates ISGs expression but has no effects on IFN- $\alpha$ and IFN- $\beta$ production}

We next analyzed the expression of ISGs in A549 cells in the presence of RSV. Cells were pretreated with the indicated concentrations of luteolin, followed by RSV infection, and the mRNA expression levels of MX dynamin like GTPase 1 (MX1), 2'-5'-oligoadenylate synthase 1 (OAS1) and ISG15 were determined by RT-qPCR. Luteolin itself did not induce ISGs expressions (Additional file 1: Fig. 1). However, RSV infection increases ISGs expressions, and luteolin enhances RSV-induction of ISGs expressions (Fig. 2a). ISGs can be activated by type I IFN to execute their antiviral functions; thus, we detected IFN- $\alpha$ and IFN- $\beta$ expression and secretion by RT-qPCR and ELISA, respectively. As shown in Fig. 2b, there were no large differences of IFN- $\alpha$ and IFN- $\beta$ expressions and secretions with or without luteolin treatment, indicating that luteolin has no effect on type I IFN production.

\section{Luteolin inhibits RSV replication and alleviates RSV-triggered lung injury in mice}

To characterize the effects of luteolin on RSV replication in vivo, viral replication, type I IFN production and the mouse inflammatory response were assessed following RSV infection. As predicted, we observed a decrease after luteolin treatment in viral titer (from $2034 \pm 311 \mathrm{PFU} / \mathrm{mL}$ to $1018 \pm 163 \mathrm{PFU} / \mathrm{mL}$ at $1 \mathrm{dpi}$ and from $5980 \pm 486 \mathrm{PFU} / \mathrm{mL}$ to $2180 \pm 390 \mathrm{PFU} / \mathrm{mL}$ at 3 dpi) and RSV-F mRNA expression (Fig. 3a), accompanied by an increase in OAS1, MX1 and ISG15 expressions (Fig. 3b). RSV infection significantly induced IFN- $\alpha$ and IFN- $\beta$ production in BALF, but there were no big differences in IFN- $\alpha$ and IFN- $\beta$ levels between luteolin-treated and untreated mice (Fig. 3c). This finding was consistent with the in vitro results shown in Fig. 2b. Meanwhile, lung histopathology was evaluated by H\&E staining. As shown in Fig. 3d, RSV infection caused severe pulmonary inflammation characterized by large lymphocytic infiltration and thickening of the alveolar wall, which were not observed 

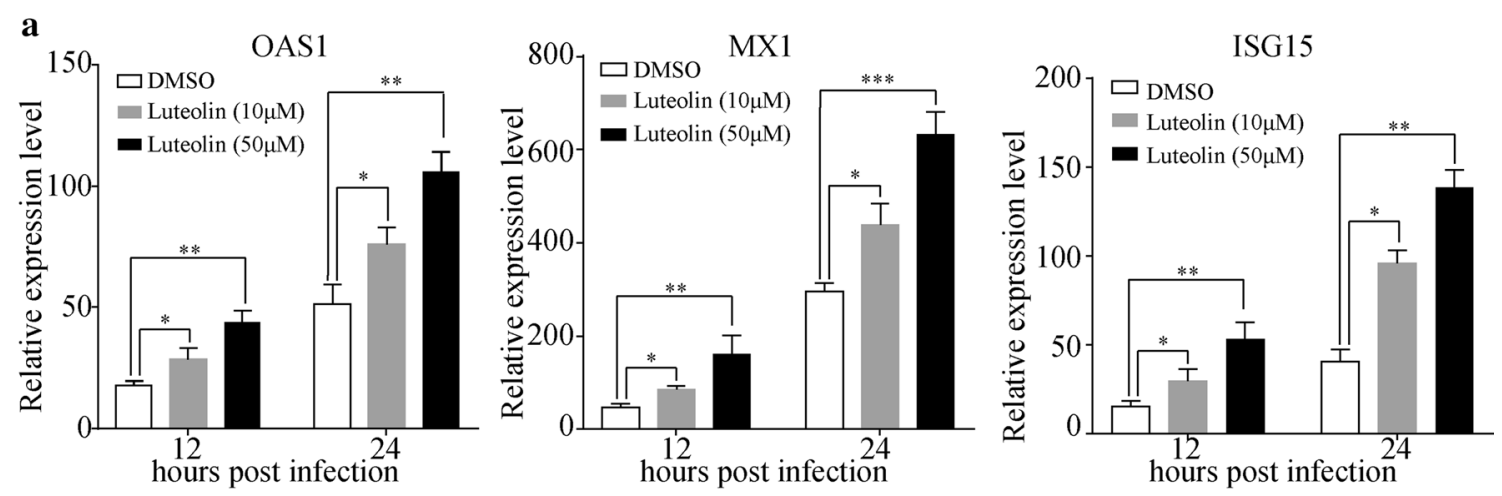

\section{b}

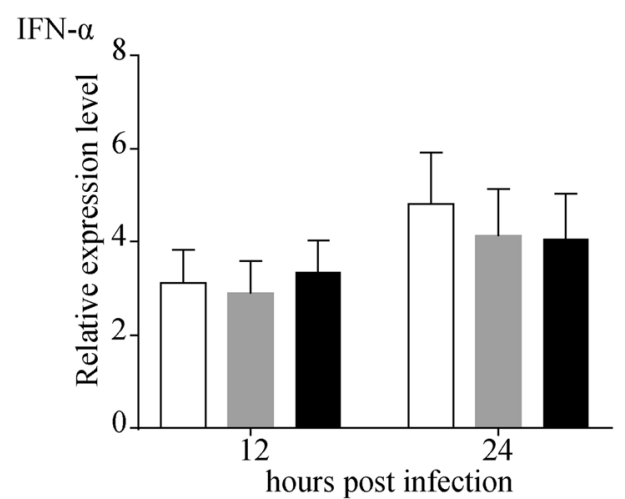

IFN- $\beta$
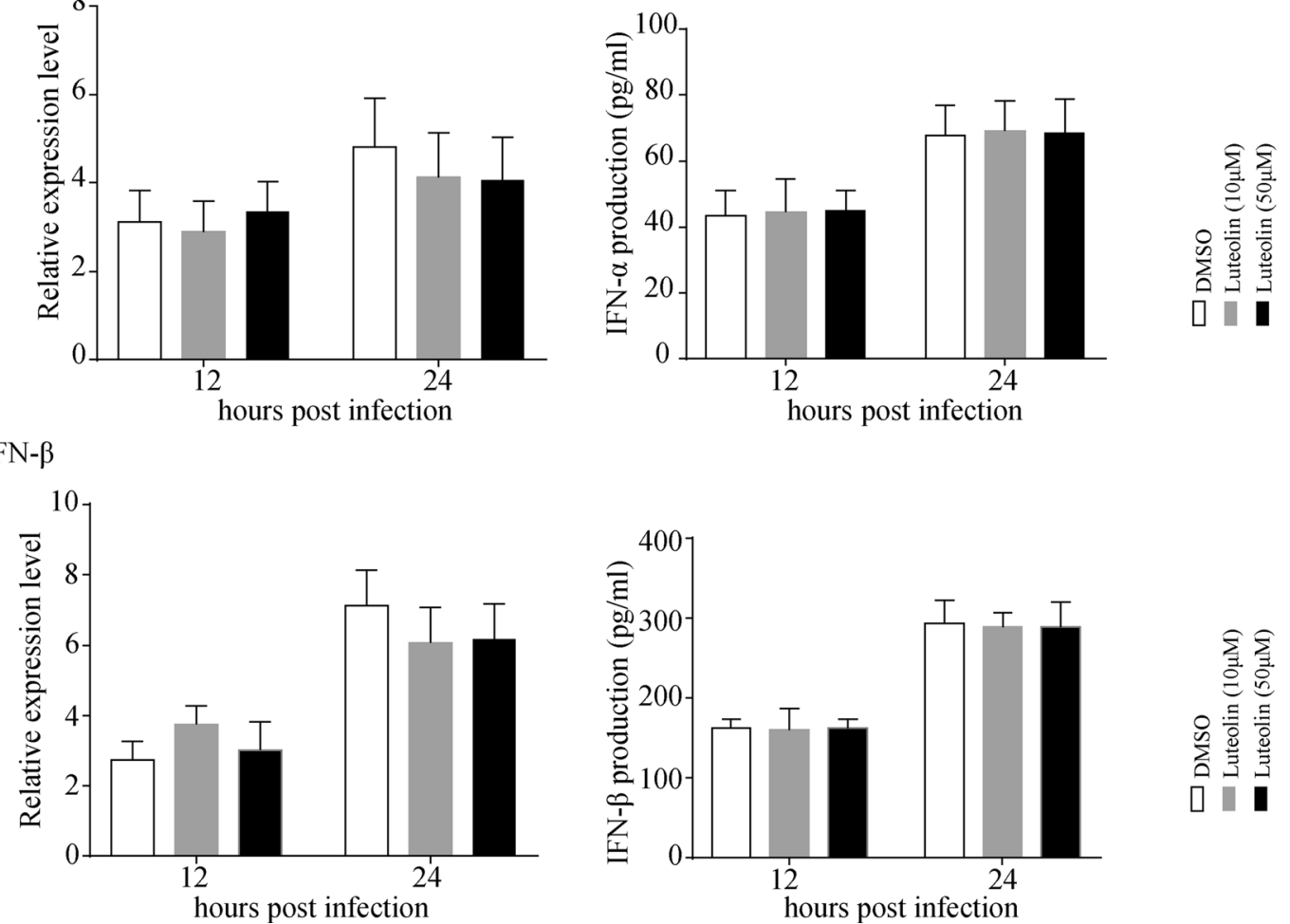

Fig. 2 Luteolin increases MX1, OAS1 and ISG15 expressions in A549 cells. A549 cells were pre-treated with the indicated concentrations of luteolin for $24 \mathrm{~h}$ before infected with RSV at MOI=0.05. At 12 or $24 \mathrm{~h}$ post infection, a RNA was extracted and RT-qPCR was performed to determine the MX1, OAS1 and ISG15 expressions. b IFN- $a$ and IFN- $\beta$ mRNA expressions or secretions in cell culture supernatants were determined by RT-qPCR or ELSIA, respectively. Data shown are means \pm SEM. Statistical significance was examined by Students' $t$-test. $P<0.05$ was considered statistically significant. ${ }^{*} P<0.05,{ }^{* *} P<0.01,{ }^{* *} P<0.001$. MX1 MX dynamin like GTPase 1, OAS1 2'-5'-oligoadenylate synthase 1, ISG15 interferon stimulated gene $15, R S V$ respiratory syncytial virus, $M O /$ multiplicity of infection

in mock-infected mice. Mice in the luteolin-treated groups showed reduced histopathological changes as the lung had less lymphocytes infiltration. We also infected the mice with higher dosage of RSV $\left(1 \times 10^{7}\right.$ PFU) and, excitingly, luteolin treatment significantly decreased the viral titer (from 10,120 $0601 \mathrm{PFU} / \mathrm{mL}$ to $3600 \pm 524 \mathrm{PFU} / \mathrm{mL}$ at $1 \mathrm{dpi}$ and from $35,980 \pm 3466$ $\mathrm{PFU} / \mathrm{mL}$ to $10,660 \pm 1031 \mathrm{PFU} / \mathrm{mL}$ at $3 \mathrm{dpi}$ ) and RSV-F mRNA expression (Fig. 3e). Thus, we concluded that luteolin inhibits RSV replication both in vitro and in vivo. 


\section{Luteolin upregulates ISGs through increased STAT1 phosphorylation}

Since luteolin could upregulate ISGs expressions but not IFN- $\alpha / \beta$ production, we then determined whether this effect is mediated through STAT1. A549 cells were pretreated with luteolin or DMSO before infected with RSV. The expression levels of p-JAK1 and p-STAT1 were detected at different hpi. Interestingly, as shown in Fig. 4a, a significant increase in STAT1 phosphorylation was detected in luteolin-treated cells, and STAT1 phosphorylation peaked at $6 \mathrm{hpi}$. However, the level of phosphorylated JAK1 remained steady throughout stimulation at different hpi. We further examined ISRE promoter activity using a luciferase reporter assay and found that luteolin significantly enhanced ISRE activity $(P<0.05)$ (Fig. $4 b)$. Taken together, these results suggested that luteolin upregulates ISGs through increased phosphorylation of STAT1. Thus, luteolin may positively regulate the type I IFN signaling pathway.

\section{Luteolin downregulates SOCS1 which negatively regulates STAT1 phosphorylation}

To gain insight into the mechanisms by which luteolin modulates STAT1 signaling, the expression levels of SOCS1, SOCS2, SOCS3, SOCS6, CIS, SHP-1 and SHP-2, proteins which are known to negatively regulate STAT1, were analyzed. A decrease in SOCS1 expression was observed in luteolin-treated A549 cells and MEFs (Fig. 5a, b). Thus, we overexpressed SOCS1 in A549 cells to determine the effects of SOCS1 in this process. As shown in Fig. 5c, overexpression of SOCS1 partly reversed luteolin-induced viral inhibition of which the viral titer changed from $1542 \pm 212 \mathrm{PFU} / \mathrm{mL}$ to $2267 \pm 145 \mathrm{PFU} / \mathrm{mL}(P<0.05)$ at $24 \mathrm{hpi}$ and $5233 \pm 419$ $\mathrm{PFU} / \mathrm{mL}$ to $10,017 \pm 700 \mathrm{PFU} / \mathrm{mL}(P<0.01)$ at $48 \mathrm{hpi}$, as well as RSV-F mRNA expression. We also detected MX1, OAS1 and ISG15 expressions by RT-qPCR (Fig. 5d) and ISRE promoter activity by luciferase assay (Fig. 5e). As expected, luteolin significantly decreased the ISGs expressions and ISRE activity, while SOCS1 rescued this decrease $(P<0.05)$. These results suggest that luteolin upregulates STAT1 phosphorylation by decreasing
SOCS1 expression, thus increasing the expression of ISGs to inhibit RSV replication.

\section{Luteolin downregulates SOCS1 expression by inducing miR-155 expression}

Previous studies reported that SOCS1 is a target of miR155 [22, 23]; therefore, we speculated that miR-155 plays a key role in the mechanism by which luteolin attenuates SOCS1 expression in A549 cells. To evaluate this hypothesis, we first detected miR-155 expression in cells pretreated with luteolin by RT-qPCR (Fig. 6a). The expression level of miR-155 was significantly increased in the luteolin-stimulated groups compared with that in the control groups $(P<0.05)$. Then, we performed a luciferase reporter assay in A549 cells. As shown in Fig. 6b, c, miR155 significantly inhibited the luciferase reporter activity of the Wt but not Mut SOCS1 3'-UTR, indicating that SOCS1 is a direct target of miR-155. Western blotting analysis of SOCS1 in miR-155 mimic- or miR-155 inhibitor-transfected cells confirmed that miR-155 downregulated the expression of SOCS1 in A549 cells infected with RSV (Fig. 6d, e).

Having demonstrated that SOCS1 is a direct target of miR-155, we further explored the effect of miR-155 on luteolin-induced viral inhibition. A549 cells were transfected with miR-155 mimic or miR-155 inhibitor before being treated with luteolin. Inhibition of miR-155 rescued the inhibitory effect of luteolin, whereas upregulation of miR-155 enhanced this inhibitory effect (Fig. 6f). These effects were tightly related to changes in ISG expression (Fig. 6g).

\section{Discussion}

In the present study, the effects of luteolin on RSV replication were examined with the aim of determining the potential antiviral mechanism of luteolin. The significant observations of this study are as follows: (1) luteolin inhibits RSV replication both in vitro and in vivo; (2) luteolin upregulates MX1, OAS1 and ISG15 expression and STAT1 phosphorylation but has no significant effects on type I IFN production; (3) luteolin downregulates the expression of SOCS1, which is a negative regulator of

\footnotetext{
(See figure on next page.)

Fig. 3 Luteolin inhibits RSV replication in vivo. BALB/c mice were intraperitoneally injected with luteolin before intranasally infected with $5 \times 10^{5}$ PFU RSV. At 1- or 3-days post infection, a Virus titer and RSV-F mRNA expression in lung homogenates were measured by plaque assay and RT-qPCR, respectively. $\mathbf{b}$ The mRNA level of MX1, OAS1 and ISG15 in lung tissues were detected by RT-qPCR. $\mathbf{c}$ IFN- $a$ and IFN- $\beta$ mRNA expression in lung tissues or secretion in BALF were determined by RT-qPCR or ELISA, respectively. $\mathbf{d}$ Lung tissues were collected for H\&E staining and the representative histological changes of the lung were presented (original magnification $200 \times$, Scale bar: $50 \mu \mathrm{m}$ ). e BALB/c mice were intraperitoneally injected with luteolin before intranasally infected with $1 \times 10^{7} \mathrm{PFU}$ RSV. At 1- or 3-days post infection, virus titer and RSV-F mRNA expression in lung homogenates were measured by plaque assay and RT-qPCR, respectively. Data shown are means \pm SEM. Statistical significance was examined by Students' $t$-test. $P<0.05$ was considered statistically significant. ${ }^{*} P<0.05,{ }^{* *} P<0.01,{ }^{* *} P<0.001$. RSV respiratory syncytial virus, MX1 MX dynamin like GTPase 1, OAS1 2'-5'-oligoadenylate synthase 1, ISG15 interferon stimulated gene 15, IFN interferon, BALF bronchial alveolar lavage fluid
} 

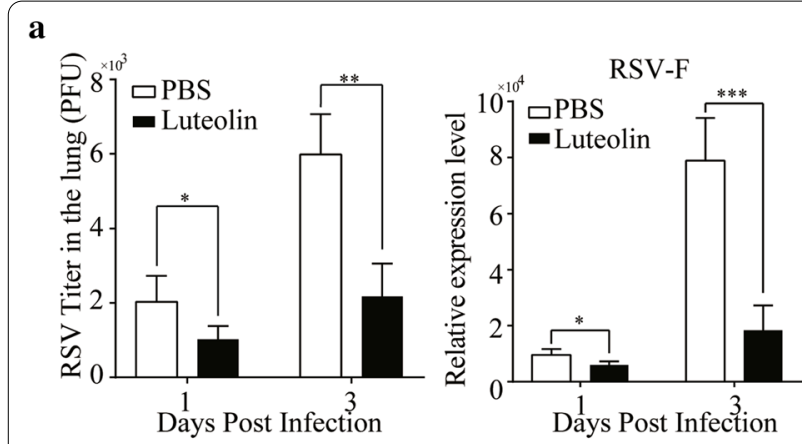

e

b
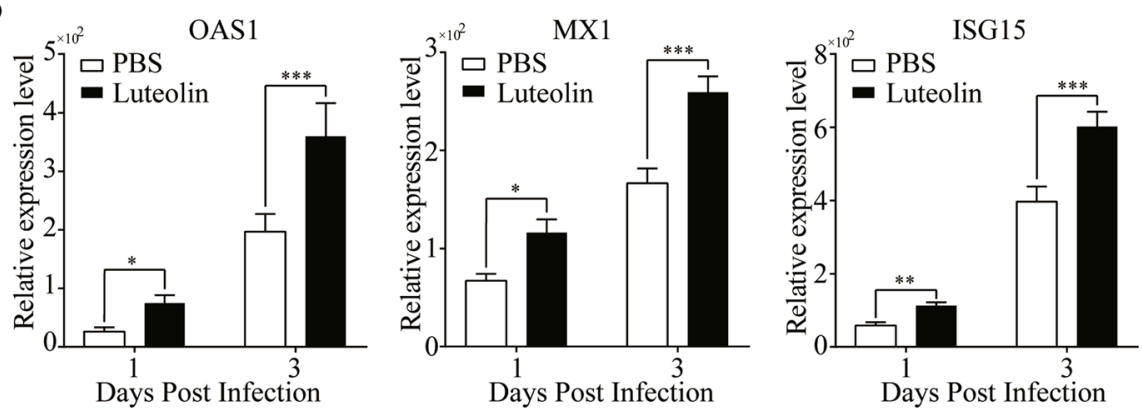

c
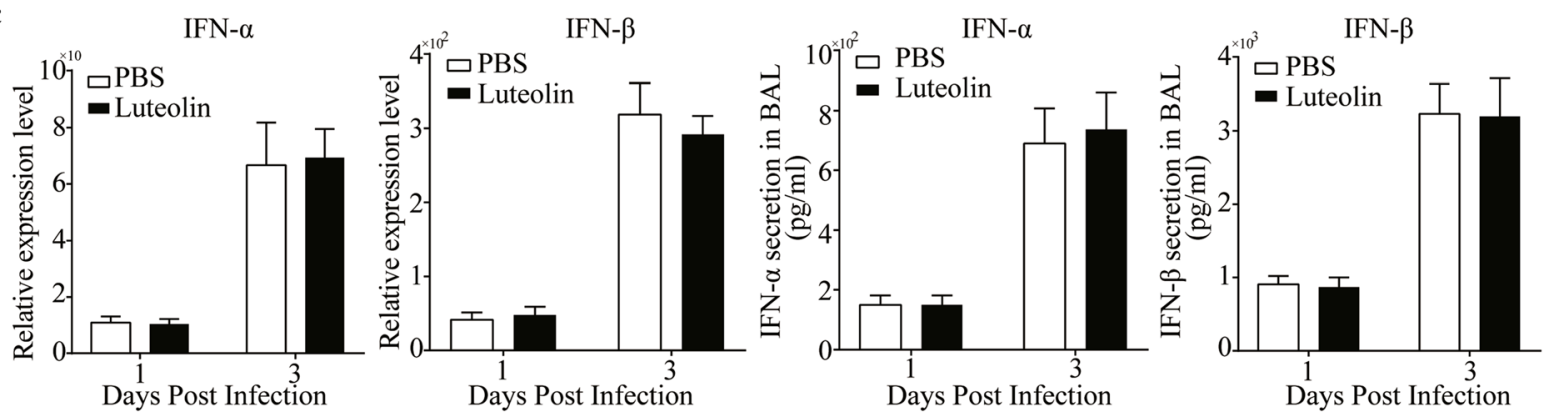

d
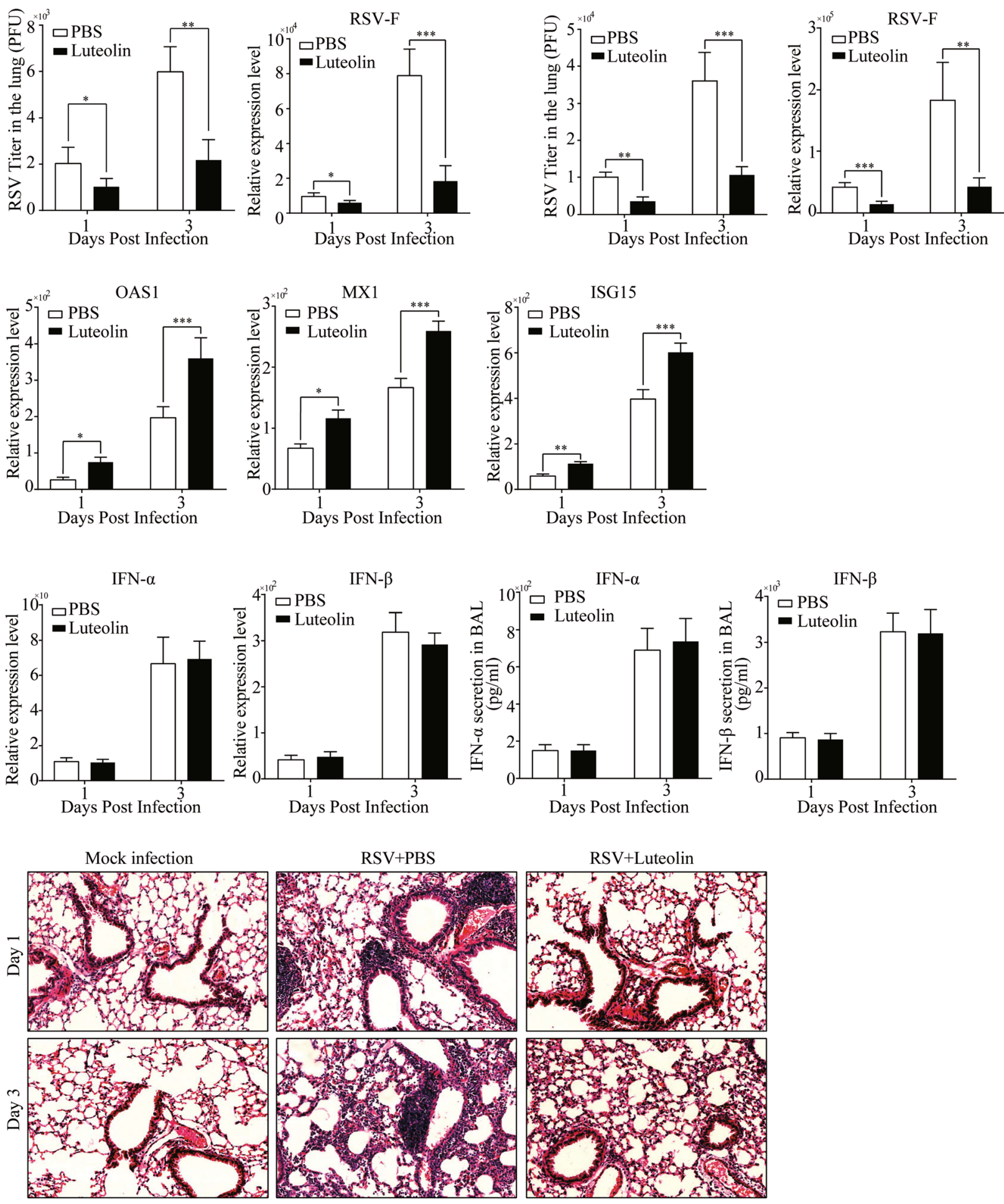


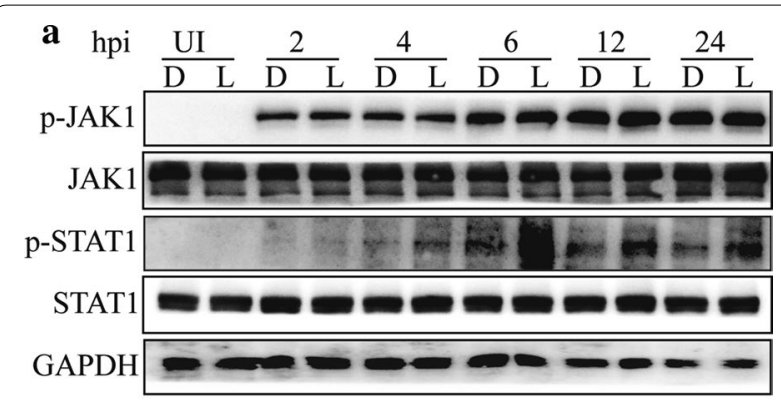

b

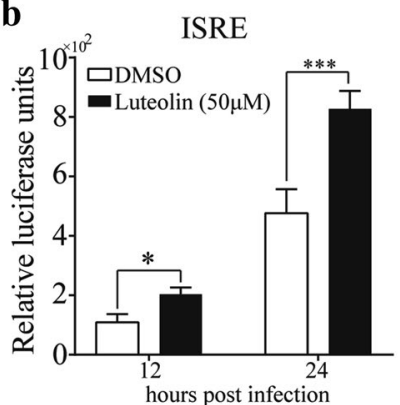

Fig. 4 Luteolin enhances STAT1 phosphorylation and ISRE luciferase activity. a A549 cells were pre-treated with $50 \mu \mathrm{M}$ luteolin for $24 \mathrm{~h}$ before infected with $\mathrm{RSV}$ at $\mathrm{MOI}=0.05$. At the indicated hours post infection, proteins were extracted for western blotting to detect the JAK, STAT1 phosphorylation. b A549 cells were transfected with pISRE-TA-luc for $24 \mathrm{~h}$ and cells were treated with luteolin for $24 \mathrm{~h}$ before infected with RSV. At 12 or $24 \mathrm{~h}$ post infection, cells were collected, and luciferase activities were determined. Data shown are means \pm SEM. Statistical significance was examined by Students' $t$-test. $P<0.05$ was considered statistically significant. ${ }^{*} P<0.05$, ${ }^{* * *} P<0.001$. STAT1 signal transducers and activators of transcription 1, MO/ multiplicity of infection, JAK Janus-activated kinase, ISRE interferon-stimulated response element, $R S V$ respiratory syncytial virus

Studies have reported that luteolin exerts various effects via miRNA modulation. Luteolin can inhibit tumorigenesis and induce the apoptosis of non-small cell lung cancer cells, gastric cancer cells and esophageal cancer cells via upregulation of miR-34a [24-26]. Luteolin inhibits the proliferation and induces the apoptosis of prostate cancer cells by downregulating miR-301 [27]. Luteolin was also reported to inhibit ischemia/reperfusion-induced myocardial injury via downregulation of miRNA-208b-3p [28]. In our study, we also found that luteolin can inhibit A549 cells replication in a dose- and time-dependent manner (Fig. 1b). Thus, we speculated that the viral inhibition may be partly related to the cell's death. As a result, the concentrations at 10 and $50 \mu \mathrm{M}$ of luteolin were chosen for the following experiments at which the inhibition rates of cells proliferation were $12.27 \%$ and $26 \%$, respectively at 96 h post stimulation. Consistently, miR-155 expression was upregulated in A549 cells after treatment with luteolin. However, luteolin has been found to decrease miR-155 expression in both gastric cancer and breast cancer cells $[29,30]$. This finding is very intriguing and requires further study.

JAK/STAT1 activation results in the induction of various antiviral genes and the suppression of cytokine signaling (SOCS) genes, which form a negative feedback loop for IFN signaling [31]. RSV infection in A549 cells induces SOCS1 and SOCS3 expressions, which further reduces STAT phosphorylation and facilitates the virus survival [32]. In our study, we also observed the induced expressions of SOCS1 and SOCS3 (Fig. 5a). However, after luteolin treatment, SOCS1 was downregulated, decreasing the attenuation of STAT1 phosphorylation. This result implies that luteolin can enhance the antiviral effects of IFN $\alpha / \beta$ during RSV infection.

MiR-155 plays crucial roles in the immune response, tumorigenesis and stem cell differentiation [33-36] and has been reported to target and repress many genes including SOCS1, TNF- $\alpha$, and SHIP1 [18-20]. Dudda et al. reported that miR-155 and its target gene, SOCS1, are key regulators of effector $\mathrm{CD} 8(+) \mathrm{T}$ cells as they affect cytokine signaling through STAT5 [37]. Wang et al. found that in acute pancreatitis, miR-155 targets SOCS1 to regulate the Th17 cell/Treg ratio, thus mediating disease severity [38]. MiR-155 was also shown to function

\footnotetext{
(See figure on next page.)

Fig. 5 Over-expression of SOCS1 reverses the anti-viral effects of luteolin. a A549 cells were pre-treated with $50 \mu \mathrm{M}$ luteolin for $24 \mathrm{~h}$ before infected with $\mathrm{RSV}$ at $\mathrm{MOI}=0.05$. At the indicated hours post infection, proteins were extracted for western blotting to detect the SOCS1, CIS, SOCS2, SOCS3, SOCS6, SHP-1 and SHP-2 expressions. b MEFs were pre-treated with $50 \mu \mathrm{M}$ luteolin for $24 \mathrm{~h}$ before infected with RSV at MOI $=0.05$. At $24 \mathrm{hpi}$, proteins were extracted for western blotting to detect the SOCS1 expression. A549 cells were transfected with SOCS1 plasmid or control plasmid. $24 \mathrm{~h}$ later, cells were stimulated with luteolin for $24 \mathrm{~h}$ before infected with RSV. $\mathbf{c}$ At the indicated hours post infection, virus titer or RSV-F mRNA expression was determined by plaque assay or RT-qPCR, respectively. $\mathbf{d}$ At the indicated hours post infection, cells were collected for RNA extraction and RT-qPCR was performed to detect the MX1, OAS1 and ISG15 expressions. e A549 cells were co-transfected with ISRE-luc and SOCS1 plasmid or control plasmid. $24 \mathrm{~h}$ later, cells were stimulated with luteolin for $24 \mathrm{~h}$ before infected with RSV. At 12 or $24 \mathrm{~h}$ post infection, cells were collected, and luciferase activities were determined. Data shown are means \pm SEM. Statistical significance was examined by Students't-test. $P<0.05$ was considered statistically significant. ${ }^{*} P<0.05,{ }^{* *} P<0.01,{ }^{* * *} P<0.001$. SOCS suppressor of cytokine, RSV respiratory syncytial virus, CIS cytokine-induced STAT inhibitor, SHP protein-tyrosine phosphatase, $\mathrm{MO}$ I multiplicity of infection
} 
a

hpi $\frac{U I}{\mathrm{D} L} \frac{}{\mathrm{D} L \mathrm{~L}} \frac{4}{\mathrm{D} L} \frac{6}{\mathrm{D} L \mathrm{~L}} \frac{12}{\mathrm{D} L} \frac{24}{\mathrm{D} L}$

$\begin{array}{lllllllllll}1 & 0.89 & 1.2 & 1.78 & 1.98 & 1.70 & 6.12 & 1.12 & 8.6 & 1.13\end{array}$

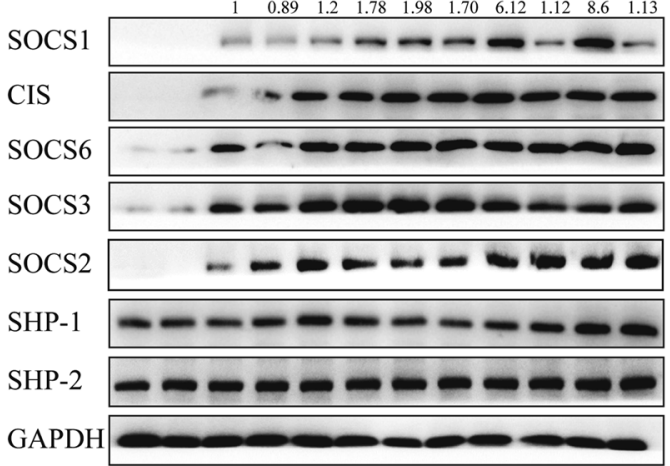

b

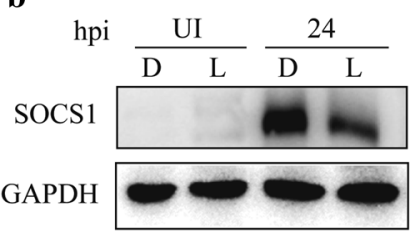

RSV

RSV-F expression

c

$2010^{\times 10^{3}}$ Vector+Luteolin
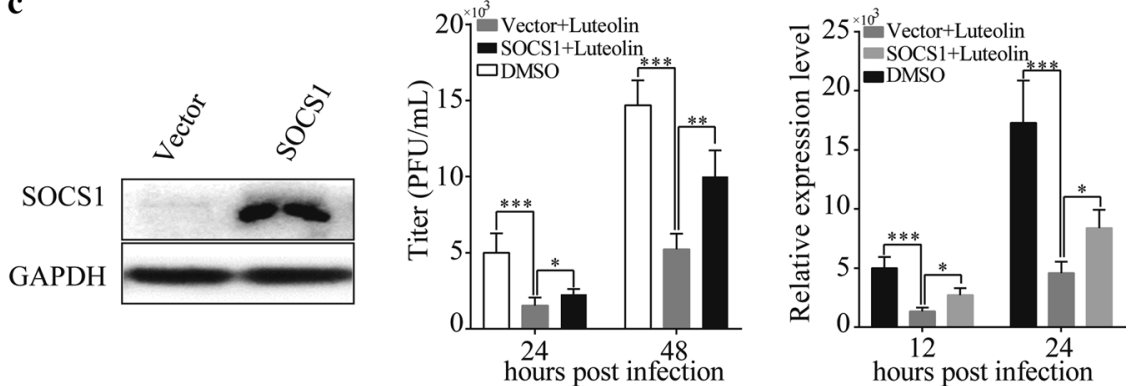

d

DMSO

Vector+Luteolin

SOCS1+Luteolin
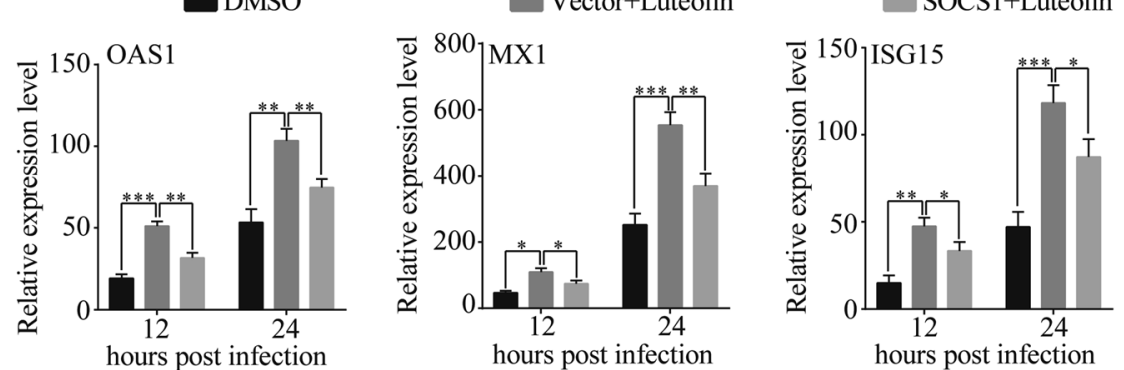

e

ISRE

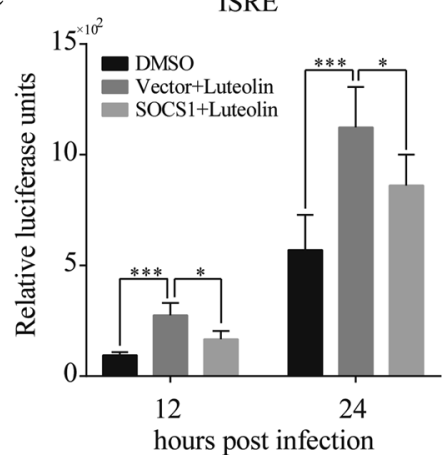




\section{a}

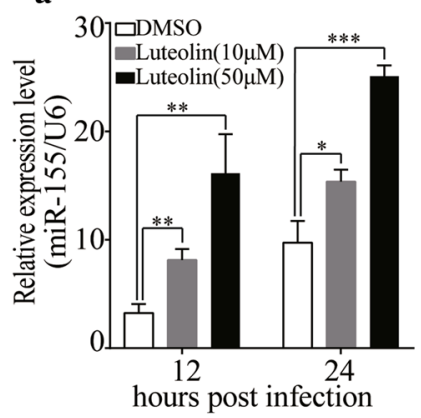

c

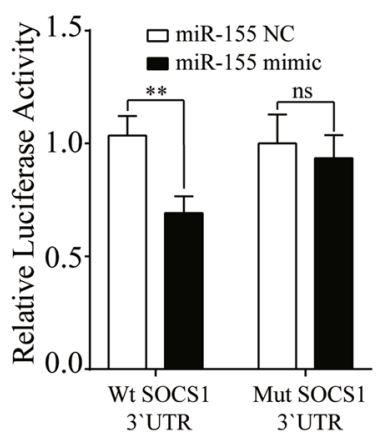

d

miR-155 expression
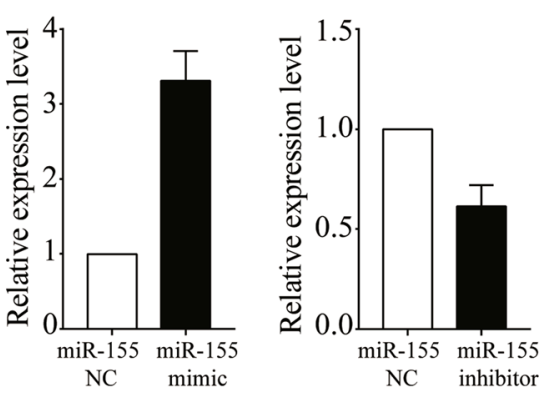

e b
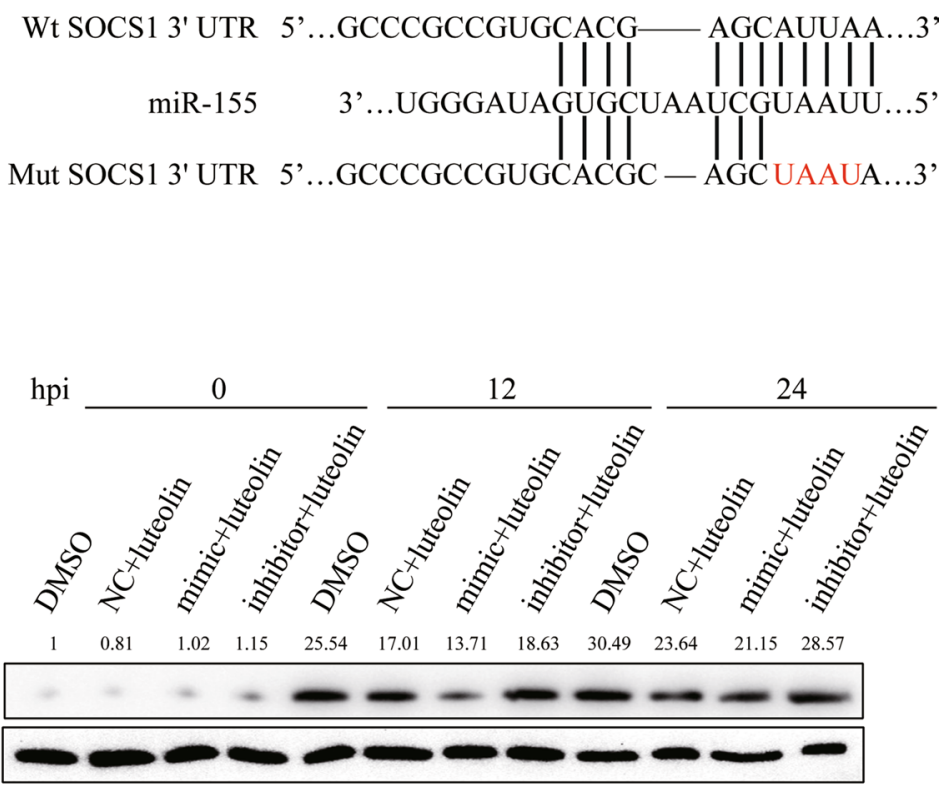

f
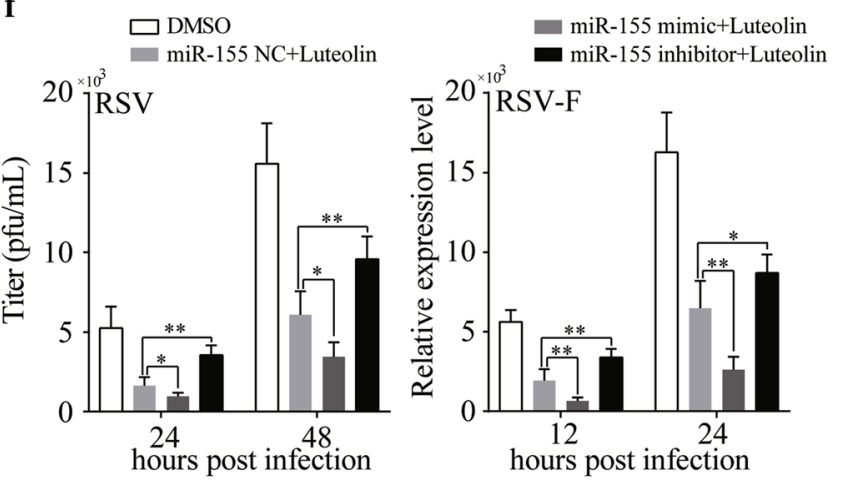

g
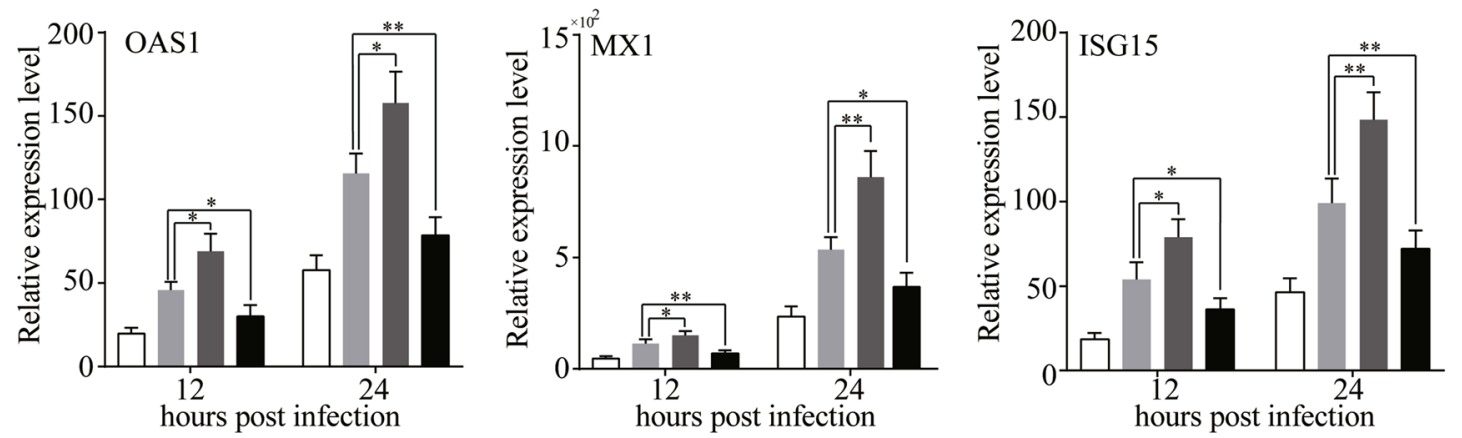

as a pro-proliferative regulator during liver regeneration by facilitating the cell cycle and directly targeting SOCS1 [39]. In this study, we demonstrated that SOCS1 is the direct target of miR-155, which is consistent with the results of previous reports. Inhibition of miR-155 restored SOCS1 expression, and overexpression of miR155 decreased SOCS1 expression. 
(See figure on previous page.)

Fig. 6 SOCS1 is a target of miR-155. a A549 cells were pre-treated with luteolin for $24 \mathrm{~h}$ before infected with RSV. At 12 or $24 \mathrm{~h}$ post infection, cells were collected for RT-qPCR to detect the miR-155 expression. b Putative miR-155 binding sites in the SOCS1 3'-UTR. The sites targeted by mutagenesis are indicated. c Dual luciferase reporter assay was performed in A549 cells that co-transfected with pcDNA-Luc Wt SOCS1 or PCDNA-Luc Mut SOCS1 and miR-155 mimic or miR-155 negative control to detect the luciferase activity at $48 \mathrm{~h}$ after transfection. Renilla luciferase activities normalized for firefly luciferase are presented. A549 cells were transfected with miR-155 mimc or miR-155 inhibitor for 24 h, d The mRNA expression of miR-155 was detected by RT-qPCR. e Cells were treated with luteolin for $24 \mathrm{~h}$ before infected with RSV and proteins were extracted at the indicated hours post infection to detect the SOCS1 expression by Western Blotting. $\mathbf{f}$ At the indicated hours post infection, virus titer or RSV-F mRNA expression were determined by plaque assay or RT-qPCR, respectively. $\mathbf{g}$ At the indicated hours post infection, cells were collected for RNA extraction and RT-qPCR was performed to detect the MX1, OAS1 and ISG15 expressions. Data shown are means \pm SEM. Statistical significance was examined by Students't-test. $P<0.05$ was considered statistically significant. ${ }^{*} P<0.05$, ${ }^{* *} P<0.01,{ }^{* *} P<0.001$. SOCS suppressor of cytokine, RSV respiratory syncytial virus, $\mathrm{MOI}$ multiplicity of infection, STAT1 signal transducers and activators of transcription 1, JAK Janus-activated kinase

\section{Conclusion}

Taken together, the results of the current study demonstrated that luteolin can inhibit RSV replication both in vitro and in vivo through the induction of miR-155, which targets SOCS1, leading to enhanced activation of STAT1 phosphorylation and ISG expression. These results may facilitate the development of valuable therapeutic strategies to treat RSV infection by enhancing the STAT1 signaling pathway with traditional Chinese medicine or miRNAs.

\section{Supplementary information}

Supplementary information accompanies this paper at https://doi. org/10.1186/s12985-020-01451-6.

Additional file 1. Figure 1: Luteolin cannot induce MX1, OAS1, ISG15, IFN- $\alpha$, IFN- $\beta$ expressions in A549 cells. A549 cells were treated with luteolin at $50 \mu \mathrm{M}$ for 24 or 48 hours before RNA was extracted and RTqPCR was performed to determine the MX1, OAS1, ISG1, IFN- $\alpha$ and IFN- $\beta$ expressions.

\section{Abbreviations}

RSV: Respiratory syncytial virus; ISG: Interferon-stimulated gene; JAK: Janus kinase; STAT1: Signal transducer and activator of transcription 1; SOCS1: Suppressor of cytokine signaling 1; miR-155: MicroRNA-155; IFN: Interferon; hpi: Hours post infection; PFU: Plaque forming units; dpi: Days post infection.

\section{Acknowledgements}

Not applicable.

\section{Authors' contributions}

$S W, T L, Y Y$ and $B C$ participated in the conception and design of the study. $S W, T L, Y Y$ and GZ performed the statistical analysis and were involved in the interpretation of data and the preparation of the figures. SW and $B C$ reviewed the results and participated in the discussion of the data. YY, TL, SW and BC prepared the manuscript and revised it. All authors read and approved the manuscript and agreed to be personally accountable for the author's own contributions and to ensure that questions related to the accuracy or integrity of any part of the work. All authors read and approved the final manuscript.

\section{Funding}

Not applicable.

\section{Availability of data and materials}

All data supporting the conclusions of this article are included in this published article.

\section{Ethics approval and consent to participate}

All animal experiments in this study received ethical approval from the Animal Care and Use Committee of Zhejiang University. Experiments and animal care were performed according to the approved protocols (Permit number is 2017-135).

\section{Consent for publication}

Not applicable.

\section{Competing interests}

The authors have no conflicts of interest to disclose.

\section{Author details}

${ }^{1}$ Department of Colorectal Surgery, The First Affiliated Hospital, Zhejiang University School of Medicine, 79 Qingchun Road, Hangzhou 310003, Zhejiang, People's Republic of China. ${ }^{2}$ Department of Cardiology, The Second Affiliated Hospital, Zhejiang University School of Medicine, Hangzhou 310009, Zhejiang, People's Republic of China.

Received: 31 May 2020 Accepted: 5 November 2020

Published online: 25 November 2020

\section{References}

1. Rima B, Collins P, Easton A, Fouchier R, Kurath G, Lamb RA, Lee B, Maisner A, Rota P, Wang L, Ictv Report C. ICTV virus taxonomy profile: pneumoviridae. J Gen Virol. 2017;98:2912-3.

2. Nair H, Nokes DJ, Gessner BD, Dherani M, Madhi SA, Singleton RJ, O'Brien $\mathrm{KL}$, Roca A, Wright PF, Bruce N, et al. Global burden of acute lower respiratory infections due to respiratory syncytial virus in young children: a systematic review and meta-analysis. Lancet. 2010;375:1545-55.

3. Falsey AR, Hennessey PA, Formica MA, Cox C, Walsh EE. Respiratory syncytial virus infection in elderly and high-risk adults. N Engl J Med. 2005;352:1749-59.

4. Mazur NI, Higgins D, Nunes MC, Melero JA, Langedijk AC, Horsley N, Buchholz UJ, Openshaw PJ, McLellan JS, Englund JA, et al: The respiratory syncytial virus vaccine landscape: lessons from the graveyard and promising candidates. Lancet Infect Dis 2018.

5. Liu SY, Sanchez DJ, Cheng G. New developments in the induction and antiviral effectors of type I interferon. Curr Opin Immunol. 2011;23:57-64.

6. Anson DM, Wilcox RM, Huseman ED, Stump TA, Paris RL, Darkwah BO, Lin S, Adegoke AO, Gryka RJ, Jean-Louis DS, Amos S: Luteolin Decreases EGFR-Mediated Cell Proliferation and Induces Apoptosis in Glioblastoma Cell Lines. Basic Clin Pharmacol Toxicol 2018.

7. Aziz N, Kim MY, Cho JY: Anti-inflammatory effects of luteolin: A review of in vitro, in vivo, and in silico studies. J Ethnopharmacol 2018.

8. Yang JT, Wang J, Zhou XR, Xiao C, Lou YY, Tang LH, Zhang FJ, Qian LB. Luteolin alleviates cardiac ischemia/reperfusion injury in the hypercholesterolemic rat via activating Akt/Nrf2 signaling. Naunyn Schmiedebergs Arch Pharmacol. 2018;391:719-28.

9. Nabavi SF, Braidy N, Gortzi O, Sobarzo-Sanchez E, Daglia M, SkalickaWozniak K, Nabavi SM. Luteolin as an anti-inflammatory and neuroprotective agent: A brief review. Brain Res Bull. 2015;119:1-11. 
10. Wu CC, Fang CY, Hsu HY, Chen YJ, Chou SP, Huang SY, Cheng YJ, Lin SF, Chang Y, Tsai CH, Chen JY. Luteolin inhibits Epstein-Barr virus lytic reactivation by repressing the promoter activities of immediate-early genes. Antiviral Res. 2016;132:99-110.

11. Peng M, Watanabe S, Chan KWK, He Q, Zhao Y, Zhang Z, Lai X, Luo D, Vasudevan SG, Li G. Luteolin restricts dengue virus replication through inhibition of the proprotein convertase furin. Antiviral Res. 2017;143:176-85.

12. Fan W, Qian S, Qian P, Li X. Antiviral activity of luteolin against Japanese encephalitis virus. Virus Res. 2016;220:112-6.

13. Manvar D, Mishra M, Kumar S, Pandey VN. Identification and evaluation of anti hepatitis C virus phytochemicals from Eclipta alba. J Ethnopharmacol. 2012;144:545-54.

14. Bai L, Nong Y, Shi Y, Liu M, Yan L, Shang J, Huang F, Lin Y, Tang H. Luteolin inhibits hepatitis B virus replication through extracellular signal-regulated kinase-mediated down-regulation of hepatocyte nuclear factor 4alpha expression. Mol Pharm. 2016;13:568-77.

15. Liu CW, Lin HW, Yang DJ, Chen SY, Tseng JK, Chang TJ, Chang YY. Luteolin inhibits viral-induced inflammatory response in RAW264.7 cells via suppression of STAT1/3 dependent NF-kappaB and activation of HO-1. Free Radic Biol Med. 2016;95:180-9.

16. Li J, Tan S, Kooger R, Zhang C, Zhang Y. MicroRNAs as novel biological targets for detection and regulation. Chem Soc Rev. 2014;43:506-17.

17. Rupaimoole R, Slack FJ. MicroRNA therapeutics: towards a new era for the management of cancer and other diseases. Nat Rev Drug Discov. 2017;16:203-22.

18. Chen S, Wang L, Fan J, Ye C, Dominguez D, Zhang Y, Curiel TJ, Fang D, Kuzel TM, Zhang B. Host miR155 promotes tumor growth through a myeloid-derived suppressor cell-dependent mechanism. Cancer Res. 2015;75:519-31.

19. Bruen R, Fitzsimons S, Belton O. miR-155 in the Resolution of Atherosclerosis. Front Pharmacol. 2019;10:463.

20. Bayraktar R, Van Roosbroeck K. miR-155 in cancer drug resistance and as target for miRNA-based therapeutics. Cancer Metastasis Rev. 2018;37:33-44.

21. Liau NPD, Laktyushin A, Lucet IS, Murphy JM, Yao S, Whitlock E, Callaghan K, Nicola NA, Kershaw NJ, Babon JJ. The molecular basis of JAK/STAT inhibition by SOCS1. Nat Commun. 2018;9:1558.

22. Pathak S, Grillo AR, Scarpa M, Brun P, D'Inca R, Nai L, Banerjee A, Cavallo D, Barzon L, Palu G, et al. MiR-155 modulates the inflammatory phenotype of intestinal myofibroblasts by targeting SOCS1 in ulcerative colitis. Exp Mol Med. 2015;47:e164.

23. Ye J, Guo R, Shi Y, Qi F, Guo C, Yang L. miR-155 Regulated Inflammation Response by the SOCS1-STAT3-PDCD4 Axis in Atherogenesis. Mediators Inflamm. 2016;2016:8060182.

24. Jiang ZQ, Li MH, Qin YM, Jiang HY, Zhang X, Wu MH. Luteolin inhibits tumorigenesis and induces apoptosis of non-small cell lung cancer cells via regulation of MicroRNA-34a-5p. Int J Mol Sci. 2018;2018:19.

25. Wu H, Huang M, Liu Y, Shu Y, Liu P. Luteolin induces apoptosis by upregulating miR-34a in human gastric cancer cells. Technol Cancer Res Treat. 2015;14:747-55.

26. Shi H, Zhou S, Liu J, Zhu J, Xue J, Gu L, Chen Y. miR-34a inhibits the in vitro cell proliferation and migration in human esophageal cancer. Pathol Res Pract. 2016;212:444-9.
27. Han K, Meng W, Zhang JJ, Zhou Y, Wang YL, Su Y, Lin SC, Gan ZH, Sun YN, Min DL. Luteolin inhibited proliferation and induced apoptosis of prostate cancer cells through miR-301. Onco Targets Ther. 2016;9:3085-94.

28. Bian C, Xu T, Zhu H, Pan D, Liu Y, Luo Y, Wu P, Li D. Luteolin inhibits ischemia/reperfusion-induced myocardial injury in rats via downregulation of microRNA-208b-3p. PLoS ONE. 2015;10:e144877.

29. Pu Y, Zhang T, Wang J, Mao Z, Duan B, Long Y, Xue F, Liu D, Liu S, Gao Z. Luteolin exerts an anticancer effect on gastric cancer cells through multiple signaling pathways and regulating miRNAs. J Cancer. 2018;9:3669-75.

30. Sun DW, Zhang HD, Mao L, Mao CF, Chen W, Cui M, Ma R, Cao HX, Jing CW, Wang Z, et al. Luteolin inhibits breast cancer development and progression in vitro and in vivo by suppressing notch signaling and regulating MiRNAs. Cell Physiol Biochem. 2015;37:1693-711.

31. Porritt RA, Hertzog PJ. Dynamic control of type I IFN signalling by an integrated network of negative regulators. Trends Immunol. 2015;36:150-60.

32. Xu X, Zheng J, Zheng K, Hou Y, Zhao F, Zhao D. Respiratory syncytial virus NS1 protein degrades STAT2 by inducing SOCS1 expression. Intervirology. 2014;57:65-73.

33. Qiu L, Zhang Y, Do DC, Ke X, Zhang S, Lambert K, Kumar S, Hu C, Zhou Y, Ishmael FT, Gao P: miR-155 modulates cockroach allergen- and oxidative stress-induced cyclooxygenase-2 in asthma. J Immunol 2018.

34. Brown CY, Dayan S, Wong SW, Kaczmarek A, Hope CM, Pederson SM, Arnet V, Goodall GJ, Russell D, Sadlon TJ, Barry SC. FOXP3 and miR-155 cooperate to control the invasive potential of human breast cancer cells by down regulating ZEB2 independently of ZEB1. Oncotarget. 2018;9:27708-27.

35. Cao W, Gao W, Liu Z, Hao W, Li X, Sun Y, Tong L, Tang B: Visualizing miR155 to monitor breast tumorigenesis and response to chemotherapeutic drugs by a self-assembled photoacoustic nanoprobe. Anal Chem 2018.

36. Jiang J, Song Z, Zhang L. miR-155-5p promotes progression of acute respiratory distress syndrome by inhibiting differentiation of bone marrow mesenchymal stem cells to alveolar Type II epithelial cells. Med Sci Monit. 2018:24:4330-8.

37. Dudda JC, Salaun B, Ji Y, Palmer DC, Monnot GC, Merck E, Boudousquie C, Utzschneider DT, Escobar TM, Perret R, et al. MicroRNA-155 is required for effector CD8+T cell responses to virus infection and cancer. Immunity. 2013;38:742-53.

38. Wang D, Tang M, Zong P, Liu H, Zhang T, Liu Y, Zhao Y. MiRNA-155 Regulates the Th17/Treg Ratio by Targeting SOCS1 in Severe Acute Pancreatitis. Front Physiol. 2018;9:686.

39. Lin X, Chen L, Li H, Liu Y, Guan Y, Li X, Jia Z, Lin X, Jia J, Sun Y, Xiao D: miR155 accelerates proliferation of mouse hepatocytes during liver regeneration by directly targeting SOCS1. Am J Physiol Gastrointest Liver Physiol 2018.

\section{Publisher's Note}

Springer Nature remains neutral with regard to jurisdictional claims in published maps and institutional affiliations.

\footnotetext{
Ready to submit your research? Choose BMC and benefit from:

- fast, convenient online submission

- thorough peer review by experienced researchers in your field

- rapid publication on acceptance

- support for research data, including large and complex data types

- gold Open Access which fosters wider collaboration and increased citations

- maximum visibility for your research: over $100 \mathrm{M}$ website views per year
}

At BMC, research is always in progress.

Learn more biomedcentral.com/submissions 